\title{
Maternal Perceptions About Breast-milk Production Predicted the Daily Frequency of Breastfeeding in Infants of Age Up-to Six Months in Gondar Town, Northwest Ethiopia
}

\author{
(D) Abel Fekadu Dadi1,2, (1) Zelalem Mehari Nigussie3, (1) Hanna Demelash Desyibelew4 \\ ${ }^{1}$ Gondar University, College of Medicine and Health Sciences, Institute of Public Health, Department of Epidemiology and Biostatistics, Gondar, \\ Ethiopia \\ 2Flinders University, School of Public Health, College of Medicine and Public Health, Australia \\ ${ }^{3}$ Bahir Dar University, College of Medicine and Health Sciences, School of Public Health, Department of Epidemiology and Biostatistics, Bahir Dar, \\ Ethiopia \\ ${ }^{4}$ Bahir Dar University, College of Medicine and Health Sciences, School of Public Health, Department of Nutrition and Dietetics, Bahir Dar, Ethiopia
}

\begin{abstract}
Aim: The proper quantity and quality of breast-milk availability markedly influenced by the number of breastfeeding (BF) sessions per day. Consistent professional support that is information based may be crucial in improving the frequency of effective BF. Thus, we aimed to provide information on factors predicting maternal BF frequency (BFF).

Materials and Methods: A total of 861 participants were selected by using a cluster sampling method and a community based cross-sectional study design. An Online Data Collection Kit (ODK) technique was applied to collect the face-to-face interviewer administered survey from lactating women. Advanced analyses were carried out. The directly downloaded data from Google Cloud imported to Stata 14. Negative Binomial Regression was employed to model the frequency of BF and its predictors.

Results: Around $77 \%$ of mothers breastfed their infants at least 9 times per day, of which $15 \%$ of the mother's breastfed more than 12 times per day. The incidence of frequent BF increased among mothers who had postnatal follow-up [Adjusted Incidence Rate Ratio (AIRR): 1.07; 95\% confidence interval (CI): 1.01-1.13], who strongly perceived the adequacy of their breast milk production (AIRR: 1.22; 95\% CI: 1.04-1.44) and who had preterm births (AIRR: 1.06; 95\% CI: 1.02-1.13). Furthermore, a one-centimetre increase in Mid Upper Arm Circumference (MUAC) of the mothers was associated with an increased frequency of BF (AIRR: $1.02 ; 95 \% \mathrm{Cl}: 1.02-1.03$ ).

Conclusion: The ratio of lactating mothers who breastfeed their infants was found to be lower than the Ethiopia Infant and Young Child Feeding Practice guideline. The incidence rate ratio of frequent BF was directly associated with antenatal MUAC, postnatal follow-up, preterm birth, and maternal perception about breast milk production. Though BFF is one of the components of appropriate BF, this issue has received little attention in Ethiopia. Thus, frontline health professional and concerned bodies should give attention to the encouragement of the frequency of BF by giving attention to its identified predictors.
\end{abstract}

Keywords: Frequency of breastfeeding, infants aged up to six months, Ethiopia, poisson regression 


\section{Introduction}

In Ethiopia, the proportion of mothers initiating exclusive breastfeeding (EBF) has increased between the years 2005 and 2019 from 49\% to 59\% (1). However, EBF is frequently discontinued before 6 months $(1,2)$, despite current recommendations that infants should be exclusively breastfed "on-demand" (according to their appetite) until the age of 6 months of life (1,3). The proportion of exclusively breastfed infants in Ethiopia abruptly drops with age; from $73 \%$ to $68 \%$ between the ages of $0-1$ months and $2-3$ months, and further to $40 \%$ at the age of $4-5$ months (1). The frequently given reasons for this discontinuation is the perceived insufficient milk production (4-6), in other words, a woman perceiving that her supply is inadequate either to satisfy her infant's hunger or to support normal growth (7). The volume of milk consumed at each BF is directly related to the available milk volume of the breast (8). Indeed, the proper quantity and quality of breast-milk availability markedly influenced the number of BF sessions per-day (9).

Thus, exclusive BF and BF duration are correlated issues as artificial feeding during the first few days and weeks of lactation reduces the frequency of breast stimulation required to form breast tissue development and milk production (10). Artificial or formula milk is likely used by mothers who perceive that they have insufficient milk production. BF knowledge is strongly linked with BF confidence and actual lactation duration (5). Several previous studies have testified that BFF falls between the range of eight to twelve times per day $(6,8,11-13)$.

Consequently, evidence-based information can assist efforts to improve the frequency of successful BF by replacing either unskilled or inconsistent professional support. We aimed to provide information that can be used as a guide to clinicians or frontline health workers on those factors affecting BFF.

\section{Materials and Methods}

\section{Study Design and Setting}

A community-based cross-sectional study was employed to reach lactating mothers who were living in Gondar Town. From the Amhara National Regional State administrative zones. Gondar town is located in the Northern part of it at a distance of $747 \mathrm{~km}$ from Addis Ababa (the largest city and capital of Ethiopia). It has 12 counties with a total population of $333,103(14,15)$. The town has one governmental referral hospital, more than eight health centres, and more than 15 private medical clinics (16). Lactating women who were living in a randomly selected urban county (clusters) were considered as the study population.

\section{Sample Size}

A cluster sampling technique was used to select lactating mothers who had six-month-old infants. At the first stage, a lottery method was applied to find the five urban clusters and at the sec ond stage, a housing census of lactating mothers found in the five selected clusters was conducted. The desired sample size (n) was calculated in Epi-info 7 by the $s$ ingle population proportion formula $n=\frac{\left(z_{\alpha / 2}\right)^{2}}{d^{2}} p q$ by assuming $95 \%$ confidence level of, $z_{\mathrm{a} / 2}=1.96$ a margin of error of 5\%, design effect of 2, the proportion infants breastfeed more than eight times per 24-hours was $74 \%(1)$, and the non-response rate was $10 \%$. The final sample size was 650 but due to a cluster effect, all the participants within the five clusters were included and a total of 861 was finally reached.

\section{Data Collection and the Questionnaire}

A face-to-face interviewer administered a structured and pre-tested electronic-based questionnaire to collect the required data from all the participants. The online data collection and management application kit was used (17). A Lenovo-7 tablet with uploaded questionnaires was used by nine trained nurses to collect and send the data through an online Google cloud platform. To confirm consistency, the original English version of the questionnaire was translated to Amharic and back-translated to English before the actual data collection. The investigators of the study supervised the overall process of the data collection activities.

Socio-demographic characteristics such as age, educational status, income, marital status, frequency and early initiation of breastfeeding were collected by using a questionnaire. Maternal and infant nutritional status were collected using the Mid Upper Arm Circumference (MUAC) where an infant with a MUAC $\leq 110 \mathrm{~mm}$ and a mother with maternal MUAC $\leq 220 \mathrm{~mm}$ were considered malnourished (18-20). Food security was assessed using a question, "In the last three months, have you ever worried that your household would not have enough food?" with a response category of "yes" or "no". Information on maternal characteristics including pregnancy intention and perception towards breast-milk production (how satisfied they were with the amount of milk they produced for their baby) were collected. Maternal depression was assessed using the Edinburgh Postnatal Depression scale with a cut-off value of 12 or more indicating depression (21). Social support was 
assessed using the Oslo Social Support scale with a cut-off value of 9 and above indicating good support (22). Partner support was assessed by a question "My husband helps me a lot" with response options of "always", "most of the time", "some of the time", and "rarely".

\section{Data Analysis}

The data, which was stored online on the Google Cloud Platform, was directly downloaded and imported to the Stata 14 for further analysis. The data completeness was checked and further cleaning was done by running frequencies. Before further analyses were done, the nature of the data was explored through mean, median, proportion/percentage, interquartile range, standard deviations, and exploratory analysis. Preliminary findings were presented using tables. The appropriate assumptions were checked (such as equal mean and variance of the corresponding count data) and the Negative Binomial Regression Model was fitted to model factors associated with the BFF. Adjusted incidence rate ratio (AIRR) with its $95 \%$ confidence interval $(\mathrm{Cl})$ was used to report factors predicting the BFF.

\section{Statistical Analysis}

A statistically significant variable was considered at a $p$-value $\leq 0.05$ in the final model. Akaike information criterion (AIC) and Bayesian information criteria (BIC) were applied to select the model with the best fit for the data. The model with the smallest AIC and BIC was selected as the best fit model for the data and interpreted.

\section{Ethical Consideration}

The first approval was obtained from University of Gondar Institutional Review Board ethics committee (approval no: O/V/P/RCS/05/1601/2018, date: 12/06/2018). A supportive letter, which was used in Gondar town health office and respective districts, was given by the University of Gondar Research and Community Service. The purpose of the study and its objectives were explained to each participant including their right to participate or not participate in the study. A personal identifier was not used in order to protect the privacy and confidentiality of the study participants. Before the interview started, written informed consent was secured from the study participants declaring that they were willingly participating in the study. Participants who were seriously ill at the time of data collection were referred to Gondar University Specialized Hospital. Lactating mothers and infants found to be severely malnourished were also counselled about proper nutrition.

\section{Results}

\section{Baseline Characteristics of the Respondents}

A total of eight hundred and sixty-one (861) mothers were interviewed. The mean [ \pm standard deviation (SD)] age of mothers was 26.5 ( \pm 4.53 ) years. Most of the mothers $(80.7 \%)$ were orthodox Christian followers and married (96.2\%). A substantial proportion of respondents (61.6\%) had primary or above educational status, while more than two-thirds of the study participants (71\%) were housewives. Around $90 \%$ of respondents had low or medium-income with a household mean ( \pm SD) monthly income of 3,509.76 ( \pm 2977.61 birr) Ethiopian birrs (Table I). Eight hundred and twenty-five (95.8\%) and six hundred and sixty-one (76.8\%) mothers had attended Antenatal-care or were attending Postnatal-care services, respectively. Regarding pregnancy needs, seven hundred and thirty-four (85.3\%) pregnancies were planned and the majority of women had 3 or less children with a mean ( \pm SD) number of $2( \pm 1.21)$ children. Over two-thirds (69\%) of BF women strongly agreed that their breast milk production was adequate.

\section{Psychosocial Characteristics of the Respondents}

Nearly half (47\%) of lactating mothers have constant support from their husband. A significant number of (79.7\%) the participants received good social support, and the remaining had poor social support. Regarding their depression status, $6 \%$ of the mothers had depression symptoms during pregnancy and $8 \%$ of lactating mothers had depression. Daily coffee consumption was reported in $41.2 \%$ of lactating mothers.

\section{Baseline Characteristics of the Infant}

The majority (68.9\%) of the infants included in the current study were above the age of four months. About $61 \%$ of infants had initiated breastfeeding within one hour of delivery and a similar proportion (63\%) of infants had exclusive BF for up to 6 months. About 15\% and $3 \%$ of infants were preterm births or low birth weight, respectively. One hundred and twenty-two (14\%) of the infants were malnourished. About $22 \%$ and $17 \%$ of the infants had diarrhea or acute respiratory infection, respectively (Table II).

\section{Predictors of Breastfeeding Frequency Among Lactating Mothers}

Among the 861 participating lactating mothers, about $77 \%$ reported breastfeeding their infants at least 9 times per day (in 24 hours). Of these, around 15\% of mothers frequently breastfed their children more than twelve times per day. An adjusted Poisson regression model output 
Table I. Baseline-characteristics of the respondent in Gondar tow, Northwest Ethiopia $(n=861)$

\begin{tabular}{|l|l|l|}
\hline Variable & Number & $\%$ \\
\hline Age of Respondents & 280 & 32.52 \\
\hline $18-24$ & 521 & 60.51 \\
\hline $25-34$ & 60 & 6.97 \\
\hline$\geq=35$ & &
\end{tabular}

\section{Religion of Respondents}

\begin{tabular}{|l|l|l|}
\hline Orthodox & 695 & 80.72 \\
\hline Muslim & 166 & 19.28 \\
\hline
\end{tabular}

\section{Marital Status of Respondents}

\begin{tabular}{|l|l|l|}
\hline Single & 33 & 3.83 \\
\hline Married & 828 & 96.17 \\
\hline
\end{tabular}

\section{Educational Level of Respondents}

\begin{tabular}{|l|l|l|}
\hline No formal education & 110 & 12.78 \\
\hline Grade 1-8 & 221 & 25.67 \\
\hline Grade 9-12 & 321 & 37.28 \\
\hline Diploma and above & 209 & 24.27 \\
\hline
\end{tabular}

\section{Occupation of Respondents}

\begin{tabular}{|c|c|c|}
\hline Housewife & 614 & 71.31 \\
\hline Student & 13 & 1.51 \\
\hline Government employee & 123 & 14.29 \\
\hline Self-employed & 111 & 12.89 \\
\hline \multicolumn{3}{|l|}{ Income of Respondents } \\
\hline Low & 419 & 48.66 \\
\hline Medium & 353 & 41.00 \\
\hline High & 89 & 10.34 \\
\hline \multicolumn{3}{|l|}{ ANC Follow-up } \\
\hline No & 36 & 4.18 \\
\hline Yes & 825 & 95.82 \\
\hline \multicolumn{3}{|l|}{ PNC Follow-up } \\
\hline No & 200 & 23.23 \\
\hline Yes & 661 & 76.77 \\
\hline \multicolumn{3}{|l|}{ Parity } \\
\hline 1 & 331 & 38.44 \\
\hline $2-3$ & 433 & 50.29 \\
\hline $4-8$ & 97 & 11.27 \\
\hline \multicolumn{3}{|l|}{ Sex of Child Preference } \\
\hline No & 626 & 72.71 \\
\hline Yes & 235 & 27.29 \\
\hline \multicolumn{3}{|l|}{ Pregnancy Planning } \\
\hline Planned & 734 & 85.25 \\
\hline
\end{tabular}

Table I. continued

\begin{tabular}{|l|l|l|}
\hline Unplanned & 127 & 14.75 \\
\hline \multicolumn{2}{|l|}{ Breast Milk Production Perception of Respondents } \\
\hline Don't know & 18 & 2.09 \\
\hline Agree & 248 & 28.80 \\
\hline Strongly agree & 595 & 69.11 \\
\hline Antenatal-MUAC & 123 & 14.29 \\
\hline$<22 \mathrm{~cm}$ & 738 & 85.71 \\
\hline$>22 \mathrm{~cm}$ & \multicolumn{2}{|l}{} \\
\hline Postnatal-MUAC & 71 & 8.25 \\
\hline$<22 \mathrm{~cm}$ & 790 & 91.75 \\
\hline$>22 \mathrm{~cm}$ & \multicolumn{2}{|l|}{} \\
\hline MUAC: Mid Upper Arm Circumference, ANC: Antenatal care, PNC: Postnatal care \\
\hline
\end{tabular}

Table II. Baseline characteristics of infants under the age of six months in Gondar town, Northwest Ethiopia $(n=861)$

\begin{tabular}{|l|l|l|}
\hline Variables & Number & $\%$ \\
\hline Age of Infant & 268 & 31.13 \\
\hline $1-4$ months & 593 & 68.87 \\
\hline $5-6$ months &
\end{tabular}

Early Initiation of BreastFeeding

\begin{tabular}{|l|l|l|}
\hline No & 332 & 38.56 \\
\hline Yes & 529 & 61.44 \\
\hline
\end{tabular}

Exclusive BreastFeeding

\begin{tabular}{|l|l|l|}
\hline No & 316 & 36.70 \\
\hline Yes & 545 & 63.30 \\
\hline
\end{tabular}

\section{Low Birth Weight}

\begin{tabular}{|l|l|l|}
\hline No & 835 & 96.98 \\
\hline Yes & 26 & 3.02 \\
\hline
\end{tabular}

Preterm Birth

\begin{tabular}{|l|l|l|}
\hline No & 733 & 85.13 \\
\hline Yes & 128 & 14.87 \\
\hline
\end{tabular}

\section{Infant Nutritional Status}

\begin{tabular}{|l|l|l|}
\hline Normal & 739 & 85.83 \\
\hline Malnutrition & 22 & 14.17 \\
\hline
\end{tabular}

\section{Diarrhea}

\begin{tabular}{|l|l|l|}
\hline No & 714 & 82.93 \\
\hline Yes & 147 & 17.07 \\
\hline Acute Respiratory Infection & 675 & 78.40 \\
\hline No & 186 & 21.60 \\
\hline Yes & &
\end{tabular}


revealed that the incidence of frequent breastfeeding increased among lactating mothers who had postnatal follow-up (AIRR: 1.07; 95\% Cl: 1.01-1.13), who strongly agreed that their breast milk production was adequate (AIRR: 1.22; 95\% Cl: 1.04-1.44), and who had preterm births (AIRR: 1.06; 95\% Cl: 1.02-1.13). A one-centimetre increase in MUAC of the mothers was found to be associated with an increase in EBF (AIRR: 1.02; 95\% Cl: 1.02-1.03) (Table III).

\section{Discussion}

Inappropriate breastfeeding practices significantly impair the health, development and survival of infants and improving these practices could save thousands of infant lives each year (2). The first few hours and days of a newborn's life are a critical window for establishing lactation through the early initiation of $\mathrm{BF}, \mathrm{EBF}$, and an increased frequency of breastfeeding. The current study aimed to provide information that can be used as a guide to clinicians or frontline health workers when advising mothers about proper breastfeeding.

Most (77\%) of the mothers reported breastfeeding their infants at least 9 times per day (in 24 hours), which is similar to a study from Southern Ethiopia with a rate of $74 \%$ and Addis Ababa city with a rate of $76 \%(23,24)$. The Ethiopia IYCF guideline recommends lactating women breastfeed infants at least 10-12 times per day (25). With respect to this, only $58 \%$ achieved this recommendation. In addition, early initiation of breastfeeding and EBF were $61 \%$ and $63 \%$ respectively, which are also below the recommended IYCF guideline (3). Compared to the current study, lower BFF was reported in Indonesia with a rate of $53.6 \%$ (13). These possible differences might be due to socio-demographic differences such as maternal education or employment status. Highly educated mothers are more

Table III. Poisson regression model to identify factors associated with BFF among lactating mothers in XX, 2019 ( $n=861$ )

\begin{tabular}{|c|c|c|c|}
\hline Variables & Frequency (\%) & IRR, 95\% CI & AIRR, 95\% CI \\
\hline Antenatal MUAC & $861(100 \%)$ & $1.03(1.02-1.04)$ & $1.02(1.002-1.03)^{*}$ \\
\hline Postnatal MUAC & $861(100 \%)$ & $1.02(1.01-1.04)$ & $1.00(0.98-1.02)$ \\
\hline \multicolumn{4}{|l|}{ PNC Follow-up } \\
\hline No & $200(23.23)$ & 1 & 1 \\
\hline Yes & $661(76.77)$ & $1.14(1.08-1.20)$ & $1.07(1.01-1.13)^{*}$ \\
\hline \multicolumn{4}{|l|}{ Preterm Birth } \\
\hline No & $733(85.13)$ & 1 & 1 \\
\hline Yes & $128(14.87)$ & 1.09 (1.04-1.16) & $1.06(1.02-1.13)^{*}$ \\
\hline
\end{tabular}

Breast Milk Production Perception of Mothers

\begin{tabular}{|c|c|c|c|}
\hline Don't know & $18(2.09)$ & 1 & 1 \\
\hline Agree & $248(28.80)$ & $1.09(0.93-1.29)$ & $1.11(0.94-1.31)$ \\
\hline Strongly agree & $595(69.11)$ & $1.24(1.06-1.45)$ & $1.22(1.04-1.44)^{*}$ \\
\hline \multicolumn{4}{|l|}{ Husband Support } \\
\hline Rarely & $52(6.04)$ & 1 & - \\
\hline Some of the time & $160(18.58)$ & $1.07(0.97-1.18)$ & $1.07(0.97-1.19)$ \\
\hline Most of the time & $247(28.69)$ & $1.05(0.95-1.16)$ & $1.07(0.97-1.19)$ \\
\hline Always & $402(46.69)$ & $1.13(1.03-1.24)$ & $1.09(0.99-1.21)$ \\
\hline \multicolumn{4}{|c|}{ Days With Disability of Mothers } \\
\hline$\leq=7$ days & $416(48.32)$ & 1 & - \\
\hline$\geq=8$ days & $445(51.68)$ & $1.07(1.03-1.12)$ & $1.04(0.89-1.09)$ \\
\hline \multicolumn{4}{|c|}{ Postnatal Depression } \\
\hline No & $69(8.01)$ & 1 & - \\
\hline Yes & $792(91.99)$ & $0.95(0.88-1.03)$ & $0.97(0.89-1.06)$ \\
\hline
\end{tabular}


likely to be employed and might not have time to frequently breastfeed, unlike those who are less educated and are often housewives. Most of the participants in the current study were housewives with a low educational status. This shows the negative effect of employment on the frequency and duration of breastfeeding (26), and most importantly $\operatorname{EBF}(25)$.

In Southeast Ethiopia, the median BFF was found to be 6 times per day (27). This is lower than our finding and this might be due to the age difference of the infants $(25,28)$ included in the study as BFF decreases as the age of the infants' increases $(27,28)$. In the first month, there is frequent breastfeeding with a short duration (lasting for 20 minutes) but, in later months, this frequency gradually decreases while the duration of breastfeeding increases $(12,29)$.

A unit increase in the antenatal MUAC of the mothers resulted in an incremental increase in BFF in this study. Opposing this, a finding from Bangladesh showed that maternal nutritional status was found to be unrelated to the frequency of breastfeeding (6). In general, a previous review (30) and cohort study (31) found an association between maternal weight and the main breastfeeding components. Thus, optimizing maternal BMI during the pre-conception period is essential, which is supported by the current findings indirectly. Unlike our findings where no association between infant nutritional status and the incidence rate ratio of BFF was determined, a study from Bangladesh stated that infant nutritional status was significantly associated with BFF (6).

In this study, mothers who had postnatal follow-up were more likely to frequently breastfeed their infants than their counterparts. This is true as postnatal followup helps to provide counselling services about appropriate breastfeeding (3). A major review approach for improving $B F$ rate noted multiple determinants and influences but $\mathrm{BF}$ counselling is one of the key interventions to improve the $B F$ rate (32). The incidence rate ratio of BFF was found to be higher among mothers who had preterm birth infants. Better counselling and support about appropriate breastfeeding to mothers of preterm infants might have enhanced their knowledge and practice on the frequency of BF. This evidence implies that the implementation of some breastfeeding counselling, such as about frequency and timing, to the lactating mothers could significantly improve breastfeeding practices.

Similarly, the incidence rate ratio of frequent breastfeeding was higher among mothers who strongly agreed that their breast milk production was enough to feed their infants. Maternal perception about insufficient milk production was found to be one of the reasons for lower BFF and discontinuing BF in another study (6). There is also evidence that, for a mother, the more productive of their breasts was used more frequently than the less productive one, and when the breastfeeding was paired, the more productive breast was offered first more frequently than the less productive one (8). To our knowledge, this investigation is the first to examine BFF in relation to an urban setting. Thus, this finding may serve as baseline information for frontlin e health workers, decision-makers and researchers. However, mothers' recall bias on BF frequency might affect the validity of this study. A prospective follow-up study that is able to observe the duration of BF for each frequent BF with the inclusion of socio-cultural variables would help to determine a more precise estimate.

\section{Conclusion}

The ratio of lactating mothers in this study who breastfeed their infants was found to be lower than the Ethiopia IYCF guideline. The incidence rate ratio of frequent breastfeeding was directly associated with antenatal MUAC, postnatal follow-up, preterm birth, and maternal perception about breast milk production. Although BFF is one of the components of appropriate $B F$, this issue has received little attention in Ethiopia. Thus, frontline health professionals and concerned bodies should give attention to the enhancement of the frequency of BF. In addition, we have also a recommendation to strengthen the public health information and education system in order to promote appropriate breast-feeding.

\section{Ethics}

Ethics Committee Approval: The first approval was obtained from University of Gondar Institutional Review Board ethics committee (approval no: O/V/P/ RCS/05/1601/2018, date: 12/06/2018).

Informed Consent: Before the interview started, a written informed consent was secured from the study participants to willingly participate in the study.

Peer-review: Externally peer-reviewed.

\section{Authorship Contributions}

Concept: A.F.D., Z.M.N., H.D.D., Design: A.F.D., Z.M.N., H.D.D., Data Collection or Processing: A.F.D., Z.M.N., H.D.D., Analysis or Interpretation: A.F.D., Z.M.N., H.D.D., Literature Search: A.F.D., Z.M.N., H.D.D., Writing: A.F.D., Z.M.N., H.D.D.

Conflict of Interest: No conflict of interest was declared by the authors. 
Financial Disclosure: The authors declared that this study received no financial support.

\section{Acknowledgments}

The authors would like to acknowledge the Gondar town health department and the respective offices for their permission to conduct this study. Likewise, we would also like to acknowledge our data collectors and the study participants for their active participation in this study.

\section{References}

1. Fellenzer IL, Cibula DA. Intendedness of pregnancy and other predictive factors for symptoms of prenatal depression in a population-based study. Matern Child Health I 2014; 18:2426-36.

2. WHO. Implementation guidance: protecting, promoting and supporting breastfeeding in facilities providing maternity and newborn services: the revised baby-friendly hospital initiative. World Health Organization, 2018.

3. WHO. Guideline: counselling of women to improve breastfeeding practices: World Health Organization. World Health Organization, 2018.

4. Hauck YL, Fenwick ), Dhaliwal SS, Butt J. A Western Australian survey of breastfeeding initiation, prevalence and early cessation patterns. Matern Child Health I 2011; 15:260-8.

5. Gatti L. Maternal perceptions of insufficient milk supply in breastfeeding. I Nurs Scholarsh 2008; 40:355-63.

6. Huffman SL, Chowdhury A, Chakraborty I, Simpson NK. Breastfeeding patterns in rural Bangladesh. Am / Clin Nutr 1980; 33:144-54.

7. Thulier $D$, Mercer J. Variables associated with breastfeeding duration. J Obstet Gynecol Neonatal Nurs 2009; 38:259-68.

8. Kent JC, Mitoulas LR, Cregan MD, Ramsay DT, Doherty DA, Hartmann PE. Volume and frequency of breastfeedings and fat content of breast milk throughout the day. Pediatrics 2006; 117:e387-95. doi: 10.1542/peds.2005-1417.

9. Salcan S, Topal I, Ates I. The frequency and effective factors of exclusive breastfeeding for the first six months in babies born in Erzincan province in 2016. Eurasian I Med 2019; 51:145-9.

10. Keenan-Devlin LS, Awosemusi YF, Grobman W, et al. Early term delivery and breastfeeding outcomes. Matern Child Health 2019; 23:1339-47.

11. Kankaew S, Daramas T, Patoomwan A. Frequency of breastfeeding, bilirubin levels, and re-admission for jaundice in neonates. Bangkok Med J 2019; 15:180.

12. Shealy KR, Scanlon KS, Labiner-Wolfe I, Fein SB, GrummerStrawn LM. Characteristics of breastfeeding practices among US mothers. Pediatrics 2008; 122(Suppl 2):S50-5. doi: 10.1542/ peds.2008-1315f.

13. Annisani N, Sabur F, Ningsi A. The relationship between early initiation of breastfeeding and frequency of breastfeeding with uterine involution in postpartum mothers at Mamajang Health Center Makassar City. Urban Health 2019; 2:97-102.

14. CSA: Population and Housing Census Report: Ethiopia. In. Addis Ababa: Central Statistical Agency, 2017.

15. Ministry of urban development and construction. Background of gondar town administration, 2016. Available from: http:// www.mudc.gov.et/web/guest
16. Gondar town health office. Zonal health office health service plan of 2010 EC (2016/2017CC). Unpublished document, 2016.

17. University of Washington. Last Accessed Date: 09.05.2019. Available from: http://opendatakit.org. Open Data Kit (ODK).

18. Mwangome $M$, Ngari $M$, Fegan $G$, et al. Diagnostic criteria for severe acute malnutrition among infants aged under $6 \mathrm{mo}$. Am J Clin Nutr 2017; 105:1415-23.

19. Chand $S$, Shah $D$, Kumar $P$, et al. Mid-upper arm circumference for detection of severe acute malnutrition in infants aged between one and six months. Indian Pediatr 2015; 52:528-32.

20. Dadi AF, Desyibelew HD. Undernutrition and its associated factors among pregnant mothers in Gondar town, Northwest Ethiopia. PLoS One 2019; 14:e0215305. doi: 10.1371/journal. pone.0215305.

21. Hanlon C, Medhin G, Alem A, et al. Detecting perinatal common mental disorders in Ethiopia: validation of the self-reporting questionnaire and Edinburgh Postnatal Depression Scale. I Affect Disord 2008; 108:251-62.

22. Nosikov A, Gudex C. Development of a common instrument for mental health. EUROHIS: Developing common instruments for health surveys. Amsterdam: IOS Press, 2003:35.

23. Hoche S, Meshesha B, Wakgari N. Sub-optimal breastfeeding and its associated factors in rural communities of hula district, southern ethiopia: a cross-sectional study. Ethiop I Health Sci 2018; 28:49-62

24. Elyas L, Mekasha A, Admasie A, Assefa E. Exclusive Breastfeeding practice and associated factors among mothers attending private pediatric and child clinics, Addis Ababa, Ethiopia: a cross-sectional study. Int / Pediatr 2017; 2017:8546192. doi: $10.1155 / 2017 / 8546192$.

25. Federal Democratic Republic of Ethiopia. National Guideline on Adolescent, Maternal Infant and Young Child Nutrition, 2016. Available from: https://apps.who.int/gb/ebwha/pdf files/ EB142/B142_22-en.pdf

26. Rollins NC, Bhandari N, Hajeebhoy N, et al. Why invest, and what it will take to improve breastfeeding practices? Lancet 2016; 387:491-504.

27. Setegn T, Belachew T, Gerbaba M, Deribe K, Deribew A, Biadgilign $\mathrm{S}$. Factors associated with exclusive breastfeeding practices among mothers in Goba district, south east Ethiopia: a crosssectional study. Int Breastfeed ) 2012; 7:17.

28. Goguikian Ratcliff B, Sharapova A, Suardi F, Borel F. Factors associated with antenatal depression and obstetric complications in immigrant women in Geneva. Midwifery 2015; 31:871-8

29. Gartner LM, Morton J, Lawrence RA, et al. Breastfeeding and the use of human milk. Pediatrics 2005; 115:496-506.

30. Wojcicki JM. Maternal prepregnancy body mass index and initiation and duration of breastfeeding: a review of the literature. J Womens Health (Larchmt) 2011; 20:341-7.

31. Chen CN, Yu HC, Chou AK. Association between maternal pre-pregnancy body mass index and breastfeeding duration in Taiwan: a population-based cohort study. Nutrients 2020; 12:2361.

32. Organization WHO. Guideline: counselling of women to improve breastfeeding practices: World Health Organization, 2018. 